\title{
Differential cAMP Signaling at Hippocampal Output Synapses
}

\author{
Christian Wozny, ${ }^{1 *}$ Nikolaus Maier, ${ }^{1 *}$ Pawel Fidzinski, ${ }^{2,3}$ Jörg Breustedt, ${ }^{1}$ Joachim Behr, ${ }^{2,3 *}$ and Dietmar Schmitz ${ }^{1 *}$ \\ ${ }^{1}$ Neuroscience Research Center, ${ }^{2}$ Department of Psychiatry and Psychotherapy, and ${ }^{3}$ Johannes Müller Institute of Physiology, Charité-Universitätsmedizin \\ Berlin, 10117 Berlin, Germany
}

cAMP is a critical second messenger involved in synaptic transmission and synaptic plasticity. Here, we show that activation of the adenylyl cyclase by forskolin and application of the cAMP-analog Sp-5,6-DCl-cBIMPS both mimicked and occluded tetanusinduced long-term potentiation (LTP) in subicular bursting neurons, but not in subicular regular firing cells. Furthermore, LTP in bursting cells was inhibited by protein kinase A (PKA) inhibitors Rp-8-CPT-cAMP and H-89. Variations in the degree of EPSC blockade by the low-affinity competitive AMPA receptor-antagonist $\gamma$-D-glutamyl-glycine ( $\gamma$-DGG), analysis of the coefficient of variance as well as changes in short-term potentiation suggest an increase of glutamate concentration in the synaptic cleft after expression of LTP. We conclude that presynaptic LTP in bursting cells requires activation of PKA by a calcium-dependent adenylyl cyclase while LTP in regular firing cells is independent of elevated cAMP levels. Our results provide evidence for a differential role of cAMP in LTP at hippocampal output synapses.

Key words: bursting; cAMP; forskolin; LTP; subiculum; hippocampus

\section{Introduction}

Short- and long-term changes in synaptic efficacy are known to be important in learning and memory. cAMP is an important second messenger and its crucial role in learning and memory has been provided by many genetic and pharmacological studies (for review, see Nguyen and Woo, 2003; Ferguson and Storm, 2004). Genetic inactivation of the cAMP signaling pathway results in learning and memory impairment (Wu et al., 1995; Wong et al., 1999), whereas transgenic mice with increased cAMP levels show improved memory (Wang et al., 2004). Activation of the adenylyl cyclase, which converts ATP in cAMP, by forskolin, or the application of cAMP analogues facilitates the release of neurotransmitter (ChavezNoriega and Stevens, 1992; Huang et al., 1994; Weisskopf et al., 1994; Salin et al., 1996).

The subiculum is the main hippocampal output region serving as an interface between the hippocampus proper and the neocortex. The importance of the subiculum during encoding and retrieval of learned information has been recently demonstrated (Gabrieli et al., 1997; Zeineh et al., 2003; Deadwyler and Hampson, 2004); however, little is known about the signaling mechanism involved in synaptic

\footnotetext{
Received 0ct. 15, 2008; accepted Nov. 4, 2008.

This work was supported by Deutsche Forschungsgemeinschaft grants to J. Behr (SFB-TR3-B4, GRK 1123) and to D.S. (Emmy Noether-Programm, SFB 618 and 665, BCCNB, Exc257). We are grateful to S. Walden and A. Schönher for technical assistance. We also thank the members of the Schmitz laboratory for critical discussions and S. R. Williams for his support.

${ }^{*}$ C.W., N.M. J. Behr, and D.S. contributed equally to this work.

Correspondence should be addressed to either of the following: Christian Wozny at his present address: Medical Research Council Laboratory of Molecular Biology, Hills Road, Cambridge CB2 0QH, UK, E-mail: cwozny@mrc-Imb. cam.ac.uk; or Dietmar Schmitz, Neuroscience Research Center, Charité-Universitätsmedizin Berlin, Charitéplatz 1, 10117 Berlin, Germany, E-mail: dietmar.schmitz@charite.de.

D0I:10.1523/JNEUROSCI.4973-08.2008

Copyright $\odot 2008$ Society for Neuroscience $\quad 0270-6474 / 08 / 2814358-05 \$ 15.00 / 0$
}

plasticity within the subiculum (Commins et al., 1998; Kokaia, 2000; Huang and Kandel, 2005; Fidzinski et al., 2008; Wozny et al., 2008). Subicular pyramidal cells have been classified into bursting and regular firing cells (Stewart and Wong, 1993; Taube, 1993; Staff et al., 2000; Jung et al., 2001; Menendez de la Prida et al., 2003; Wozny et al., 2003). Bursting cells fire a burst of action potentials upon depolarizing current injection. In regular firing cells, prolonged depolarization causes either a single action potential or trains of single spikes, respectively. Recently, we provided evidence for two different forms of long-term potentiation (LTP) at CA1-subiculum synapses that correlate with the discharge properties of the subicular pyramidal cell (Wozny et al., 2008). Here, we report that LTP in bursting cells requires activation of PKA via a calcium-dependent adenylyl cyclase, while LTP in regular firing cells is independent of elevated cAMP levels. Our results provide further evidence that at CA1-subiculum synapses, the firing pattern of the postsynaptic target determines the signaling mechanism involved in synaptic plasticity.

\section{Materials and Methods}

Slice preparation. Experiments were performed in accordance to national and international guidelines as recently described (Wozny et al., 2008). Briefly, rat brain slices $(300 \mu \mathrm{m})$ were prepared in saccharose-based ACSF (in mmol/L: $\mathrm{NaCl} 87, \mathrm{NaH}_{2} \mathrm{PO}_{4} 1.25, \mathrm{KCl} 2.5, \mathrm{NaHCO}_{3} 26, \mathrm{MgCl}_{2}$ $7, \mathrm{CaCl}_{2} 0.5$, saccharose 75 , and glucose 25 ) and stored in physiological ACSF solution (containing in mmol/L: $\mathrm{NaCl} 129, \mathrm{NaH}_{2} \mathrm{PO}_{4} 1.25, \mathrm{KCl} 3$, $\mathrm{MgSO}_{4} 1.8, \mathrm{CaCl}_{2} 2, \mathrm{NaHCO}_{3} 21$, and glucose 10 , saturated with $95 \% \mathrm{O}_{2}$ and $5 \% \mathrm{CO}_{2}$ at a $\mathrm{pH}$ of 7.4).

Electrophysiology. Recordings were done in the middle portion of the subiculum that receives synaptic input from the middle subfield of CA1 in whole-cell patch-clamp near physiological temperature (Wozny et al., 2008). Patch-clamp electrodes (2-4 $\mathrm{M} \Omega$ ) were filled with (in $\mathrm{mM}$ ): K-gluconate 135, HEPES 10, Mg-ATP 2, $\mathrm{KCl} 20$, and EGTA 0.2; pH was adjusted to 7.2 with $\mathrm{KOH}$. Depolarizing current steps were applied to 
characterize the cells' discharge behavior. Excitatory postsynaptic responses were evoked by alvear stimulation. Experiments were done in the presence of the $\mathrm{GABA}_{\mathrm{A}}$ receptor-antagonist gabazine. To induce LTP, four tetani of high-frequency stimulation were applied at $100 \mathrm{~Hz}$ for $1 \mathrm{~s}$ with $10 \mathrm{~s}$ intertrain intervals. Paired-pulse facilitation (PPF) was investigated by analyzing the ratio of second to the first synaptic response (EPSC2/EPSC1, interpulse interval $50 \mathrm{~ms}$ ). All values are expressed as means \pm SEM and statistical comparison was done by applying Student's $t$ test or an ANOVA test. Significance level was set to $p<0.05$.

Drugs. Gabazine (SR 95531; $1 \mu \mathrm{M}$ ) and 1,9-dideoxyforskolin (50 $\mu \mathrm{M})$ were purchased from Sigma-Aldrich, forskolin ( 5 and $50 \mu \mathrm{M}), 2,3-$ dioxo-6-nitro1,2,3,4-tetrahydrobenzo(f)quinoxaline-7-sulfonamide (NBQX, 40-100 $\mathrm{nM})$, and $\gamma$-D-glutamyl-glycine $(\gamma$-DGG, $1 \mathrm{~mm})$ from Tocris/Biozol. To block PKA with H-89 (10 $\mu \mathrm{M}$, Sigma) and Rp-8-CPT-cAMP (100 $\mu \mathrm{M}$, Biolog), slices were incubated for at least $1 \mathrm{~h}$ before recordings were started.

\section{Results}

Elevation of cAMP is known to enhance transmitter release at the hippocampal mossy fiber synapse (Huang et al., 1994; Weisskopf et al., 1994), in the cerebellum (Salin et al., 1996), the amygdala (López de Armentia and Sah, 2007), and the prefrontal cortex (Huang and $\mathrm{Hsu}, 2006)$. Subicular pyramidal cells display regular firing or bursting behavior in response to depolarizing current pulses (Fig. 1A) (Stewart and Wong, 1993; Taube, 1993; Staff et al., 2000). To test whether cAMP plays a role in LTP at CA1-subiculum synapses, we activated adenylyl cyclase by forskolin in each cell type. Forskolin (50 $\mu \mathrm{M})$ caused a significantly stronger potentiation of evoked EPSCs in bursting cells than in regular firing cells (Fig. $1 B, C$ ). The enhancement of synaptic transmission in bursting cells was not mimicked by 1,9-dideoxyforskolin, indicating that the enhancement of synaptic transmission by forskolin is exclusively due to the activation of adenylyl cyclase (supplemental Fig. S1, available at www.jneurosci.org as supplemental material). Additionally, the cAMP-analog Sp-5,6DCl-cBIMPS also caused a facilitation of EPSCs. The enhancement evoked by manipulations that elevated cAMP was long lasting. Thus, after a brief application of forskolin $(50 \mu \mathrm{M})$, responses remained potentiated for the duration of the experiment (tested up to $60 \mathrm{~min}$ following washout of forskolin).

To exclude the possibility that the observed long-lasting effects were due to incomplete washout of forskolin, we repeated the experiments with a lower concentration of FSK $(5 \mu \mathrm{M})$. Still, we found a significant potentiation after washout (see supplemental Fig. S2, available at www.jneurosci.org as supplemental material). It has been described that cAMP can modulate background leak conductance channels (Budde et al., 1997). We took advantage of this fact to discriminate between LTP and drug washout. For this purpose we analyzed the cell's input resistance, which was reversibly decreased by $13 \pm 3 \%$ during FSK application and returned to control levels after washout (Fig. $2 \mathrm{~A}$ ). These results demonstrate a sufficient clearance of FSK from the slice.

We next examined the site at which forskolin exerts its effect in subicular bursting neurons. To this end, we monitored PPF before and after application of forskolin. During and following forskolin application we found a clear decrease in the degree of PPF. The forskolin-induced increase in synaptic strength resulted in a decrease of PPF to $84 \pm 5 \%$ of baseline values indicating a presynaptic expression of forskolin-induced facilitation (Fig. 2A,B). Further, analysis of $1 / \mathrm{CV}^{2}$ before and after forskolin was also consistent with a presynaptic site of expression (Fig. 2C).

It has been shown that variations in the degree of EPSC blockade by the low-affinity competitive AMPA receptor-antagonist $\gamma$-D-glutamyl-glycine ( $\gamma$-DGG) can be used to detect changes in the synaptic glutamate transient (Wadiche and Jahr, 2001; Shen et al., 2002; Lei and McBain, 2004). To provide further evidence
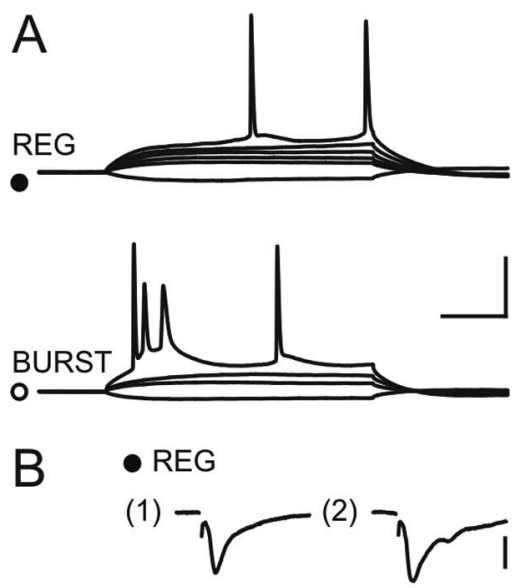

○ BURST

(1)
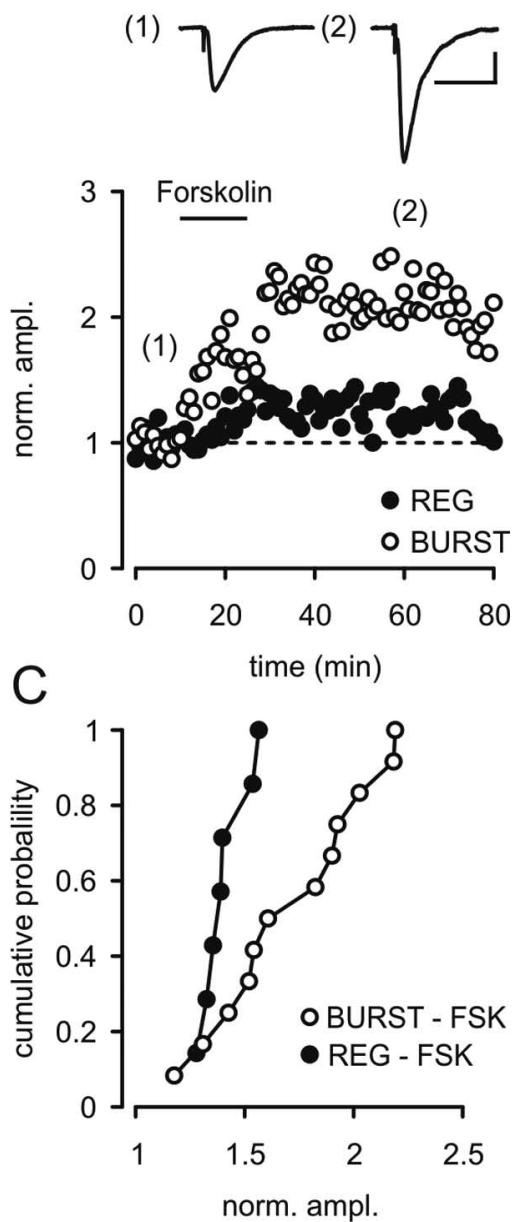

Figure 1. Cell-specific forskolin-induced LTP in burst-spiking cells. $\boldsymbol{A}$, Subicular pyramidal cells display regular firing or bursting behavior in response to depolarizing current pulses. Regular firing cells showed trains of single action potentials during depolarizing current injections. In burst firing cells, depolarization above threshold caused bursts of 2-3 action potentials followed by single action potentials or additional bursts. Calibration: $30 \mathrm{mV}, 50 \mathrm{~ms}$. B, Application of forskolin caused a long-lasting potentiation of evoked EPSCs in bursting cells, but only a moderate increase in regular firing cells. Calibration: 50 pA, 30 ms. C, Cumulative probability plots of the cell-specific effects of forskolin.

for a presynaptic expression of LTP in bursting cells, we therefore analyzed glutamate transients in the synaptic cleft before and after expression of forskolin-induced LTP. To confirm that variations in $\gamma$-DGG-induced inhibition of EPSCs reflect changes in 

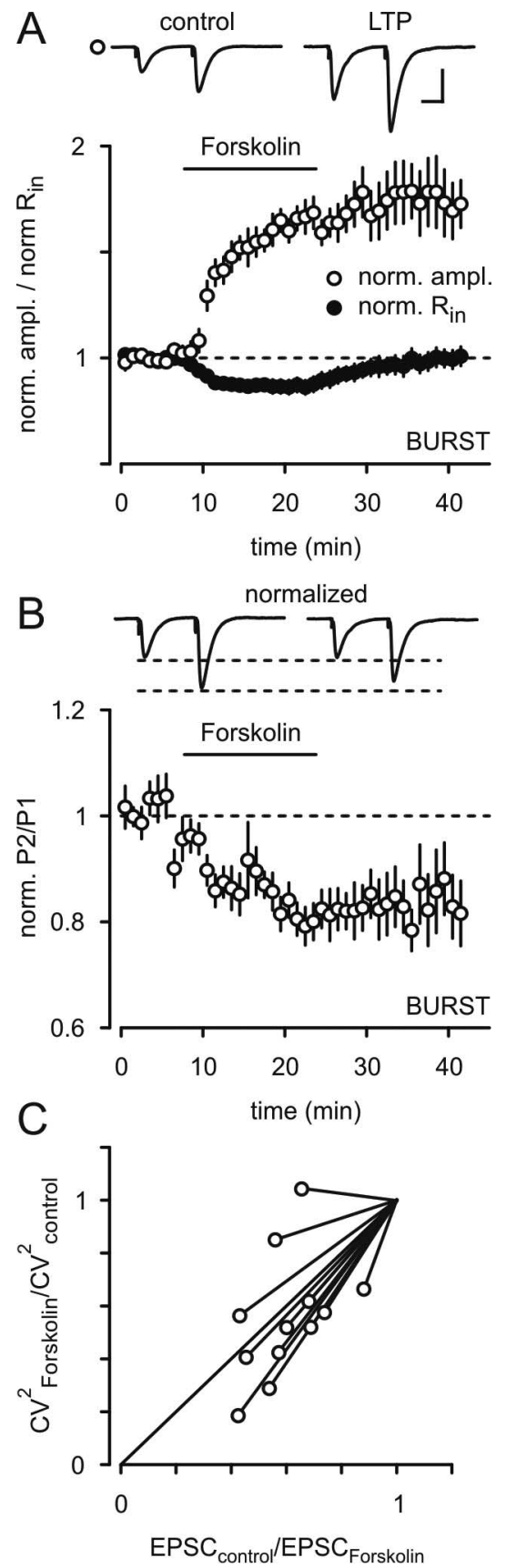

Figure 2. Forskolin-induced LTP causes a change in PPF and CV index. $A, B$, Potentiation of EPSCs recorded during application of forskolin and the corresponding alteration of PPF $(0.84 \pm$ $0.05, n=8 ; p<0.05$ ). Calibration: $150 \mathrm{pA}, 20 \mathrm{~ms}$. Please note the corresponding decrease in the input resistance during washin of forskolin (closed circles). However, after washout the input resistance returned to baseline values, while the EPSC amplitude remained potentiated.C, The calculated values for $\mathrm{CV}^{2}$ (forskolin)/ $\mathrm{CV}^{2}$ (control) plotted against ratio of the EPSC(control)/ EPSC(forskolin) fell close to the bisecting line consistent with a presynaptic effect of forskolin.

the synaptic glutamate concentration at CA1-subiculum synapses, we first increased the transmitter release probability by elevating the extracellular $\mathrm{Ca}^{2+}$ concentration and examined the corresponding changes in the degree of EPSC blockade by $\gamma$-DGG. As shown in Figure 3A, the $\gamma$-DGG-induced inhibition was significantly weaker after increasing the extracellular $\mathrm{Ca}^{2+}$ concentration from 2 to $4 \mathrm{~mm}$ (Fig. $3 A, D$ ). We next examined whether forskolin-induced LTP in subicular burst firing cells is associated with an increase of glutamate release. Indeed, EPSCs
A
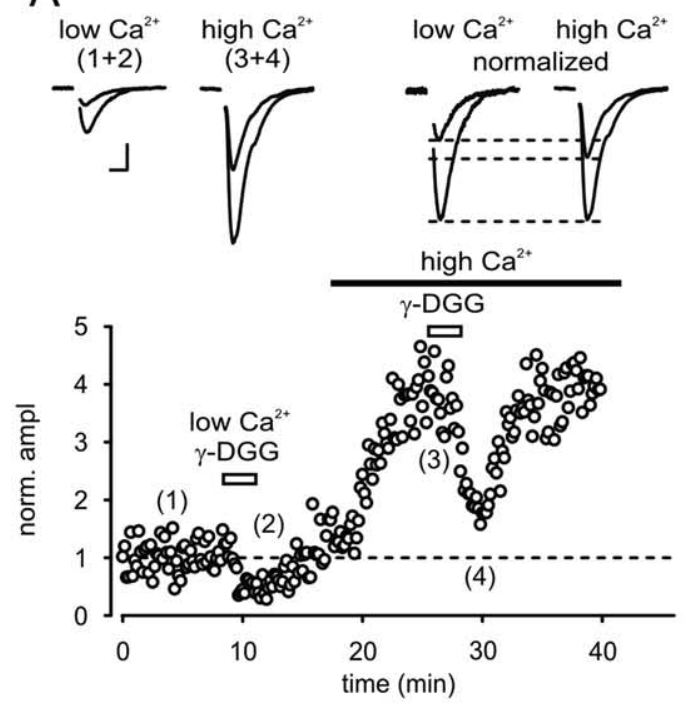

B control Forskolin control Forskolin
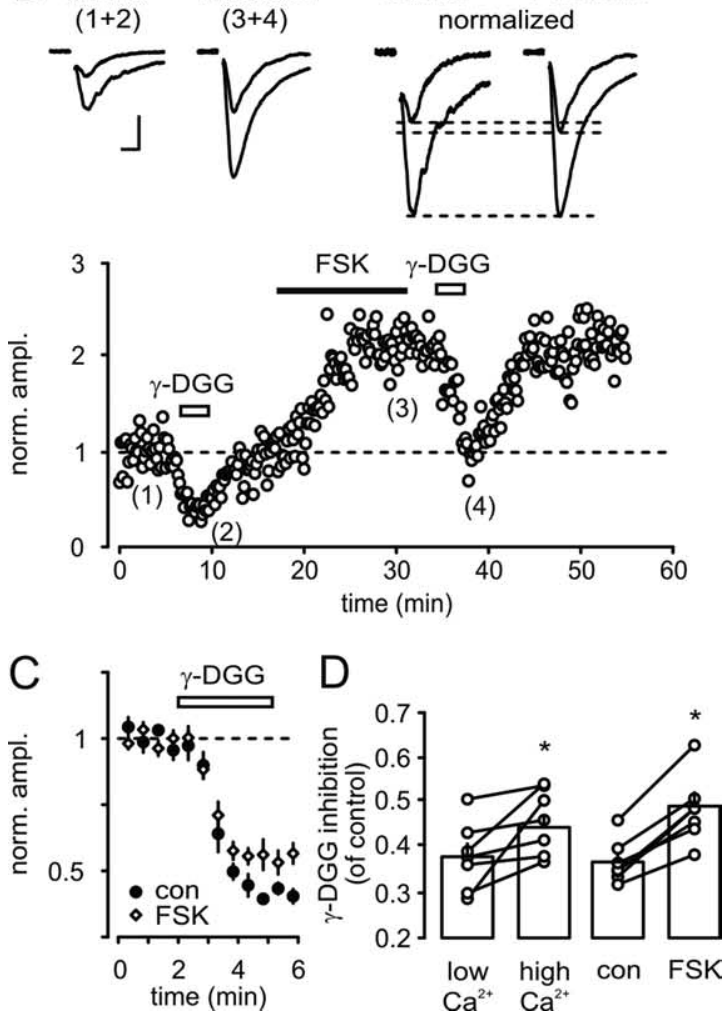

Figure 3. Forskolin-induced LTP at CA1-subicular bursting cell synapses involves an increase in glutamate release. $\boldsymbol{A}$, Increasing transmitter release probability by elevating extracellular $\mathrm{Ca}^{2+}$ from $2 \mathrm{~mm}\left(\right.$ low $\mathrm{Ca}^{2+}$ ) to $4 \mathrm{~mm}$ (high $\mathrm{Ca}^{2+}$ ) reduced the extent of $\gamma$-DGG-induced inhibition. Time course of EPSC amplitude in the presence of low (1) and high $\mathrm{Ca}^{2+}(3)$ and after application of $\gamma$-DGG $(2,4)$. Top, EPSCs recorded at the indicated time points and the corresponding normalized EPSCs. Note the reduced susceptibility of the EPSC to $\gamma$-DGG blockade when recorded in high $\mathrm{Ca}^{2+}(0.38 \pm 0.03$ vs $0.45 \pm 0.03$ of baseline, $n=7 ; p<0.05)$. $\boldsymbol{B}$, Reduced degree of EPSC blockade by $\gamma$-DGG after forskolin-induced LTP. Time course of EPSC amplitude and its suppression by $\gamma$-DGG under control conditions (2) and after forskolininduced potentiation (4). Top, EPSCs recorded at the indicated time points and the corresponding normalized EPSCs. Note the reduced extent of $\gamma$-DGG-induced inhibition after expression of $\operatorname{LTP}(0.37 \pm 0.02$ vs $0.49 \pm 0.03$ of baseline, $n=7 ; p<0.001)$. C, Normalized time course of $\gamma$-DGG-induced inhibition before (con) and after forskolin-induced potentiation (FSK). Note the reduced effect of $\gamma$-DGG following application of forskolin (FSK). D, Averaged $\gamma$-DGG-induced inhibition of EPSC amplitude in low and high $\mathrm{Ca}^{2+}$ and before (con) and after expression of LTP by forskolin (FSK). Calibration: 100 pA, $10 \mathrm{~ms}$. 

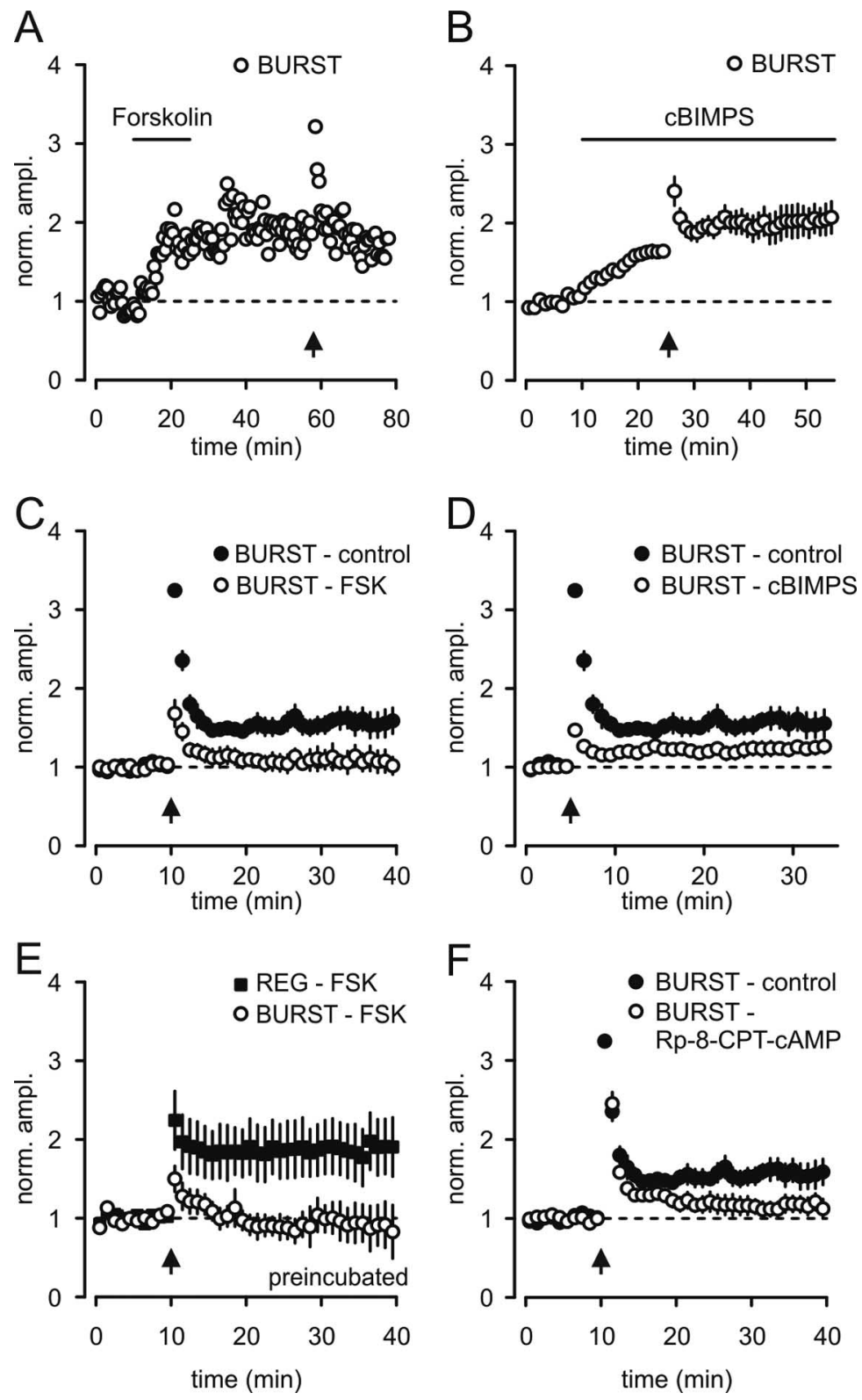

Figure 4. Forskolin and CBIMPS occlude activity-dependent LTP in burst firing neurons. $A, C$, In bursting cells forskolin-induced enhancement of EPSCs prevented tetanus-induced LTP $(1.07 \pm 0.13, n=6) . \boldsymbol{B}, \boldsymbol{D}$, Sp-5,6-DCl-CBIMPS mimicked and occluded tetanus-induced LTP in bursting neurons $(1.23 \pm 0.09, n=5)$. $\boldsymbol{E}$, In forskolin-preincubated slices, regular firing but not bursting cells express activity-dependent LTP upon tetanic stimulation $(1.76 \pm 0.31, n=6)$. $\boldsymbol{F}$, Blockade of PKA by Rp-8-CPT-cAMP prevented LTP in bursting neurons $(1.14 \pm 0.10, n=6)$.

after induction of LTP were significantly less susceptible to $\gamma$-DGG blockade than the corresponding control EPSCs, suggesting a forskolin-induced increase of glutamate concentration in the synaptic cleft (Fig. $3 B, C$ ).

How might cAMP-dependent facilitation of transmitter release be activated under physiological conditions? As cAMP-induced enhancement of synaptic strength and LTP in subicular bursting neurons both appear to be long lasting presynaptic phenomena, these two processes may involve a common pathway. Therefore, one might expect that strong activation of one process would occlude the other. Thus, we tested whether cAMP-mediated facilitation occludes LTP in subicular bursting neurons.

Indeed, in bursting cells, the enhancement of EPSCs by forskolin prevented activity-dependent LTP (Fig. 4A,C). Likewise, application of the cAMP-analog Sp-5,6-DCl-cBIMPS resulted in a facilita- tion of EPSCs that also occluded tetanusinduced LTP (Fig. 4B,D). In sharp contrast to bursting cells, in regular firing cells, we observed a robust tetanus-induced LTP in the presence of forskolin, indicating a cAMP-independent transduction mechanism (Fig. 4E).

These findings suggest that in bursting cells forskolin, the cAMP analog and LTP interact with one another indicating that they share a common process. However, it could be that either the cAMP cascade is an independent parallel process that converges on some step in the LTP pathway or the cascade is positioned in series with the LTP expression mechanism. To distinguish between these two alternatives, we determined whether blocking the cAMP cascade interrupts LTP. We therefore used Rp-8-CPTcAMP and $\mathrm{H}-89$, which are selective blockers of PKA. We found, indeed, that antagonism of PKA blocked LTP in bursting neurons (Fig. 4F; supplemental Fig. 3, available at www.jneurosci.org as supplemental material).

\section{Discussion}

Here we provide further evidence that synaptic plasticity in the subiculum is fundamentally different in regular firing and bursting neurons. Experimental elevation of cAMP either by activation of adenylyl cyclase or by a cAMP analog caused a long-lasting increase in EPSC amplitudes in bursting neurons and occluded tetanus-induced LTP. Furthermore, LTP in bursting cells was inhibited by the PKA inhibitors Rp-8-CPTcAMP and H-89. In sharp contrast, LTP in regular firing cells could still be induced in the presence of forskolin. Additionally, the forskolin-induced enhancement of EPSC amplitudes in bursting neurons caused a change in PPF. The degree of EPSC blockade by the low-affinity competitive AMPA receptor-antagonist $\gamma$-DGG suggests an increase of glutamate concentration in the synaptic cleft in burst firing cells after the application of forskolin.

Several forms of synaptic plasticity depend on adenylyl cyclase-cAMP signaling. Two of the eight known forms of adenylyl cyclase (AC) are activated by calcium, $\mathrm{ACl}$ and AC8 (for review, see Ferguson and Storm, 2004). High levels of AC1 and AC8 mRNA are found in the hippocampus, the dentate gyrus, area CA3, and area CA1 (Xia et al., 1991; Mons et al., 1995). AC1 knock-out and AC1/AC8-double knock-out mice show deficiencies in hippocampus-dependent learning (Wu et al., 1995; Wong et al., 1999). Presynaptic forms of LTP have been described to require an increase in presynaptic calcium and a subsequent increase in cAMP levels. Interestingly, both $\mathrm{AC} 1$ and $\mathrm{AC} 8$ knock-out animals exhibit defects in mossy fiber LTP (Villacres et al., 1998; Wang et al., 2003), which is known to be expressed presynaptically (Zalutsky and Nicoll, 1990; Nicoll and Schmitz, 2005). Presynaptic forms of LTP are also found at cerebellar parallel fibers (Salin et al., 1996) as well as at 
corticothalamic (Castro-Alamancos and Calcagnotto, 1999) and corticoamygdalar terminals (Humeau et al., 2003). Cerebellar parallel fiber-LTP is likewise impaired in AC1 knock-out animals.

Our observation that forskolin and cAMP analogues mimicked and occluded tetanus-induced LTP in bursting neurons, but not in regular firing cells reveals an intriguing mechanism of targetspecificity of CA1 efferents onto subicular pyramidal cells. Targetcell specific forms of synaptic plasticity have also been described at hippocampal mossy fiber synapses. Properties of mossy fiber-pyramidal cell synapses are distinct from mossy fiber-interneuron synapses (e.g., short-term plasticity, presynaptic form of LTP) (Maccaferri et al., 1998; Tóth and McBain, 2000).

Despite the growing amount of data about the cellular mechanisms of synaptic plasticity in two different types of subicular pyramidal neurons (Fidzinski et al., 2008; Wozny et al., 2008), there is a lack of functional anatomical data of these cell types. Subicular pyramidal cells project to a variety of cortical and subcortical structures (Stewart and Wong, 1993; Amaral and Witter, 1995) and they have been shown to be differentially distributed in the proximo-to-distal and deep-to-superficial axes of the subiculum (Greene and Totterdell, 1997; Staff et al., 2000; Harris et al., 2001; Menendez de la Prida et al., 2003; Jarsky et al., 2008). Future studies will have to map the target structures of bursting and regular firing cells to unravel the physiological implications of cell-specific plasticity at hippocampal output synapses.

\section{References}

Amaral DG, Witter MP (1995) The hippocampal formation. In: The rat nervous system (Paxinos G, ed), pp 443-494. New York: Academic.

Budde T, Biella G, Munsch T, Pape HC (1997) Lack of regulation by intracellular $\mathrm{Ca} 2+$ of the hyperpolarization-activated cation current in rat thalamic neurones. J Physiol 503:79-85.

Castro-Alamancos MA, Calcagnotto ME (1999) Presynaptic long-term potentiation in corticothalamic synapses. J Neurosci 19:9090-9097.

Chavez-Noriega LE, Stevens CF (1992) Modulation of synaptic efficacy in field CA1 of the rat hippocampus by forskolin. Brain Res 574:85-92.

Commins S, Gigg J, Anderson M, O'Mara SM (1998) The projection from hippocampal area CAl to the subiculum sustains long-term potentiation. Neuroreport 9:847-850.

López de Armentia M, Sah P (2007) Bidirectional synaptic plasticity at nociceptive afferents in the rat central amygdala. J Physiol 581:961-970.

Deadwyler SA, Hampson RE (2004) Differential but complementary mnemonic functions of the hippocampus and subiculum. Neuron 42:465-476.

Ferguson GD, Storm DR (2004) Why calcium-stimulated adenylyl cyclases? Physiology (Bethesda) 19:271-276.

Fidzinski P, Shor O, Behr J (2008) Target-cell-specific bidirectional synaptic plasticity at hippocampal output synapses. Eur J Neurosci 27:1111-1118.

Gabrieli JD, Brewer JB, Desmond JE, Glover GH (1997) Separate neural bases of two fundamental memory processes in the human medial temporal lobe. Science 276:264-266.

Greene JR, Totterdell S (1997) Morphology and distribution of electrophysiologically defined classes of pyramidal and nonpyramidal neurons in rat ventral subiculum in vitro. J Comp Neurol 380:395-408.

Harris E, Witter MP, Weinstein G, Stewart M (2001) Intrinsic connectivity of the rat subiculum: I. Dendritic morphology and patterns of axonal arborization by pyramidal neurons. J Comp Neurol 435:490-505.

Huang CC, Hsu KS (2006) Presynaptic mechanism underlying cAMPinduced synaptic potentiation in medial prefrontal cortex pyramidal neurons. Mol Pharmacol 69:846-856.

Huang YY, Kandel ER (2005) Theta frequency stimulation up-regulates the synaptic strength of the pathway from CA1 to subiculum region of hippocampus. Proc Natl Acad Sci U S A 102:232-237.

Huang YY, Li XC, Kandel ER (1994) cAMP contributes to mossy fiber LTP by initiating both a covalently mediated early phase and macromolecular synthesis-dependent late phase. Cell 79:69-79.

Humeau Y, Shaban H, Bissière S, Lüthi A (2003) Presynaptic induction of heterosynaptic associative plasticity in the mammalian brain. Nature 426:841-845.
Jarsky T, Mady R, Kennedy B, Spruston N (2008) Distribution of bursting neurons in the CAl region and the subiculum of the rat hippocampus. J Comp Neurol 506:535-547.

Jung HY, Staff NP, Spruston N (2001) Action potential bursting in subicular pyramidal neurons is driven by a calcium tail current. J Neurosci 21:3312-3321.

Kokaia M (2000) Long-term potentiation of single subicular neurons in mice. Hippocampus 10:684-692.

Lei S, McBain CJ (2004) Two loci of expression for long-term depression at hippocampal mossy fiber-interneuron synapses. J Neurosci 24:2112-2121.

Maccaferri G, Tóth K, McBain CJ (1998) Target-specific expression of presynaptic mossy fiber plasticity. Science 279:1368-1370.

Menendez de la Prida L, Suarez F, Pozo MA (2003) Electrophysiological and morphological diversity of neurons from the rat subicular complex in vitro. Hippocampus 13:728-744.

Mons N, Harry A, Dubourg P, Premont RT, Iyengar R, Cooper DMF (1995) Immunohistochemical localization of adenylyl cyclase in rat brain indicates a highly selective concentration at synapses. Proc Natl Acad Sci U S A 92:8473-8477.

Nguyen PV, Woo NH (2003) Regulation of hippocampal synaptic plasticity by cyclic AMP-dependent protein kinases. Prog Neurobiol 71:401-437.

Nicoll RA, Schmitz D (2005) Synaptic plasticity at hippocampal mossy fibre synapses. Nat Rev Neurosci 6:863-876.

Salin PA, Malenka RC, Nicoll RA (1996) Cyclic AMP mediates a presynaptic form of LTP at cerebellar parallel fiber synapses. Neuron 16:797-803.

Shen Y, Hansel C, Linden DJ (2002) Glutamate release during LTD at cerebellar climbing fiber-Purkinje cell synapses. Nat Neurosci 5:725-726.

Staff NP, Jung HY, Thiagarajan T, Yao M, Spruston N (2000) Resting and active properties of pyramidal neurons in subiculum and CA1 of rat hippocampus. J Neurophysiol 84:2398-2408.

Stewart M, Wong RK (1993) Intrinsic properties and evoked responses of guinea pig subicular neurons in vitro. J Neurophysiol 70:232-245.

Taube JS (1993) Electrophysiological properties of neurons in the rat subiculum in vitro. Exp Brain Res 96:304-318.

Tóth K, McBain CJ (2000) Target-specific expression of pre- and postsynaptic mechanisms. J Physiol 525:41-51.

Villacres EC, Wong ST, Chavkin C, Storm DR (1998) Type I adenylyl cyclase mutant mice have impaired mossy fiber long-term potentiation. J Neurosci 18:3186-3194.

Wadiche JI, Jahr CE (2001) Multivesicular release at climbing fiberPurkinje cell synapses. Neuron 32:301-313.

Wang H, Pineda VV, Chan GC, Wong ST, Muglia LJ, Storm DR (2003) Type 8 adenylyl cyclase is targeted to excitatory synapses and required for mossy fiber long-term potentiation. J Neurosci 23:9710-9718.

Wang H, Ferguson GD, Pineda VV, Cundiff PE, Storm DR (2004) Overexpression of type- 1 adenylyl cyclase in mouse forebrain enhances recognition memory and LTP. Nat Neurosci 7:635-642.

Weisskopf MG, Castillo PE, Zalutsky RA, Nicoll RA (1994) Mediation of hippocampal mossy fiber long-term potentiation by cyclic AMP. Science 265:1878-1882.

Wong ST, Athos J, Figueroa XA, Pineda VV, Schaefer ML, Chavkin CC, Muglia LJ, Storm DR (1999) Calcium-stimulated adenylyl cyclase activity is critical for hippocampus-dependent long-term memory and late phase LTP. Neuron 23:787-798.

Wozny C, Kivi A, Lehmann TN, Dehnicke C, Heinemann U, Behr J (2003) Comment on "On the origin of interictal activity in human temporal lobe epilepsy in vitro." Science 301:463; author reply 463.

Wozny C, Maier N, Schmitz D, Behr J (2008) Two different forms of longterm potentiation at CA1-subiculum synapses. J Physiol 586:2725-2734.

Wu Z, Thomas SA, Villacres EC, Xia Z, Simmons ML, Chavkin C, Palmiter RD, Storm DR (1995) Altered behavior and long-term potentiation in type I adenylyl cyclase mutant mice. Proc Natl Acad Sci U S A 92:220-224.

Xia ZG, Refsdal CD, Merchant KM, Dorsa DM, Storm DR (1991) Distribution of mRNA for the calmodulin-sensitive adenylate cyclase in rat brain: expression in areas associated with learning and memory. Neuron 6:431-443.

Zalutsky RA, Nicoll RA (1990) Comparison of two forms of long-term potentiation in single hippocampal neurons. Science 248:1619-1624.

Zeineh MM, Engel SA, Thompson PM, Bookheimer SY (2003) Dynamics of the hippocampus during encoding and retrieval of face-name pairs. Science 299:577-580. 